\title{
Critical Care Epidemiology and Research in the Face of a Pandemic: An Opportunity in a Crisis
}

\author{
Bharath Kumar Tirupakuzhi Vijayaraghavan ${ }^{1}$, Ramesh Venkataraman ${ }^{2}$, Nagarajan Ramakrishnan ${ }^{3}$
}

Keywords: Coronavirus, Critical care research, Pandemic.

Indian Journal of Critical Care Medicine (2020): 10.5005/jp-journals-10071-23390

\section{INTRODUCTION}

In December 2019, a novel strain of the coronavirus [now labeled severe acute respiratory syndrome coronavirus 2 (SARS CoV-2)] emerged from Wuhan (Hubei province), China, and resulted in a cluster of cases of respiratory illness with several patients proceeding onto severe acute respiratory failure. The disease which has now been labeled coronavirus disease-2019 (COVID-19) has rapidly spread and as of March 24, 2020, involves 190 countries (or territories) with 334,981 cases and 14,652 deaths globally. The World Health Organization (WHO) declared the disease a pandemic on March 11, 2020. ${ }^{2}$

In India, after an initial period of isolated reports (mostly imported cases), there has been a steep increase in the number of cases to 492 by the March 24, with 9 deaths reported. ${ }^{3}$ From initial reports, it appears that about 15 to $20 \%$ of affected patients need hospitalization and/or intensive care, ${ }^{4,5}$ with conflicting reports of the case fatality rate (anywhere between 0.4 and 9.3\%). ${ }^{6}$

While capacity building for surge, clinical management of cases, measures focused on social distancing, testing, and contact tracing are key to controlling the pandemic, we expand here on why the Indian critical care community in parallel urgently needs to focus on studying the epidemiology and facilitate clinical trials, either led locally or in collaboration with international agencies.

\section{Need for Local Epidemiology and RESEARCH}

As the number of cases spike in India, we are hurtling towards what appears to be an inevitable public health crisis of a previously unseen magnitude. The experience of different countries (e.g., China vs Italy) with the pandemic starkly highlights the differences in pathogen behavior, ability of the health system to achieve surge capacity/cope, and the effectiveness of public health measures such as social distancing, self-isolation, and quarantine. In Italy, we are now witnessing the unfolding horror of a healthcare system that has been completely overwhelmed by the pandemic with mortality rates of more than $9 \%$. Taking the conservative estimate of $5 \%$ of patients needing critical care ${ }^{5}$ this can potentially translate into hundreds of thousands of patients needing intensive care in India. It is imperative that even as we undertake preparations on a war footing, in parallel, we collate information on disease behavior, presentation, illness severity, diagnostic strategies, infection control/prevention measures, antiviral therapies trialed, innovative low-cost solutions attempted, and clinical outcomes thereof.

\author{
${ }^{1-3}$ Department of Critical Care Medicine, Apollo Hospitals, Chennai, \\ Tamil Nadu, India
}

Corresponding Author: Bharath Kumar Tirupakuzhi Vijayaraghavan, Department of Critical Care Medicine, Apollo Hospitals, Chennai, Tamil Nadu, India, Phone: +91 9591100655, e-mail: bharath@icuconsultants.com How to cite this article: Vijayaraghavan BKT, Venkataraman $R$, Ramakrishnan N. Critical Care Epidemiology and Research in the Face of a Pandemic: An Opportunity in a Crisis. Indian J Crit Care Med 2020;24(4):242-244.

Source of support: Nil

Conflict of interest: None

Given the emerging differences in epidemiology between China and other countries, we can ill-afford to rely solely on descriptions from other healthcare systems. We need accurate, timely, and credible information on disease progress across hospitals, with the ability to rapidly enable information exchange and peer support. This will be critical to the success of our systems in managing the pandemic response. It is also vital that such information exchange is enabled by standardized data collection, interpretation, and harmonization of response.

Similarly, research in India during the pandemic could potentially span several domains such as agent characterization, diagnostics, therapeutics, prevention, storage of samples, and monitoring. ${ }^{7}$ For instance, several clinical trials of potential therapies are ongoing/or in advanced stages of planning across the world. ${ }^{8}$ Trials, research, and rapid cycles of quality improvement in the face of a pandemic are vital for the generation of trustworthy estimates of effect for various interventions and in knowledge translation. While governments across the world have approved certain drugs (e.g., antiretrovirals, chloroquine) for compassionate use, only robustly designed and executed clinical trials will provide reliable estimates of efficacy and effectiveness. It is vital that Indian intensive care units (ICUs) participate in several of these studies to not only enable faster enrollment of patients but also ensure representativeness of the Indian experience. In addition, for various context-specific questions, we believe that it is important for the Indian critical care community to lead observational and interventional research. While any effort to document local singlecenter experience would be admirable and welcome, ICUs across India [and all those represented by Indian Society of Critical Care Medicine (ISCCM)] should make every effort possible to coordinate and expeditiously collate multicenter data that are generalizable. The ISCCM research committee could potentially play a vital role

(c) The Author(s). 2020 Open Access This article is distributed under the terms of the Creative Commons Attribution 4.0 International License (https://creativecommons. org/licenses/by-nc/4.0/), which permits unrestricted use, distribution, and non-commercial reproduction in any medium, provided you give appropriate credit to the original author(s) and the source, provide a link to the Creative Commons license, and indicate if changes were made. The Creative Commons Public Domain Dedication waiver (http://creativecommons.org/publicdomain/zero/1.0/) applies to the data made available in this article, unless otherwise stated. 
in enabling these collaborations and setting the research agenda during the pandemic.

\section{Opportunities and Potential Solutions for Enabling Multicenter Pandemic RESEARCH IN INDIA}

One of the key strategies that the Indian critical care community must focus is on the harmonization of data collection across public and private ICUs. Several tools are readily available for such a synchronized undertaking; one well-known example comes from the International Severe Acute Respiratory and Emerging Infection Consortium (ISARIC). The ISARIC in collaboration with WHO has a readily available template for clinical data collection. ${ }^{9}$ The ISCCM could rapidly adapt and endorse this template and enable Indian ICUs to collect information in a standardized format. Alternately, if there are concerns about data collection burden, the ISCCM could develop its own limited mandatory COVID-19 data set and provide the ICUs the option of an extended data set.

Another approach could involve the use of established registries such as the Indian Registry of IntenSive care (IRIS) and Customized, Health in Intensive Care, Trainable Research and Analysis Tool (CHITRA). ${ }^{10-12}$ The Indian Registry of IntenSive care has already enabled a diagnostic code for the pandemic "pneumonia, viral which is associated with suspected or confirmed pandemic infection" per International registry standards and has the ability to ensure standardized data collection for COVID-19. Currently, IRIS has a network of $16 \mathrm{ICU}$ and can be rapidly scaled up to enroll several other ICUs to harmonize data collection and enable evaluation of presentation, illness severity, and outcomes. IRIS minimizes data collection burden by restricting variables essential for the core data set, without the risk of losing meaningful information.

There are also several important opportunities for participation in multicenter observational and interventional studies. Several international collaborative organizations such as International Forum for Acute Care Trialists (https://www.infactglobal.org/ covid-19), ISARIC, and WHO are mobilizing and coordinating the global acute care research response. Clinical trials with innovate adaptive designs such as the randomised, embedded, multifactorial, adaptive platform trial for community-acquired pneumonia (REMAP-CAP) ${ }^{13}$ are actively enrolling, and Indian centers should strongly consider participating. In addition, existing registered trials such as the largest trial of vitamin $C$, lessening organ dysfunction with vitamin $\mathrm{C}^{14}$ have expanded their inclusion criteria to include patients with COVID-19 and sepsis. The ISCCM as the leader for the critical care community in India must work in close collaboration with the Indian Council of Medical Research (ICMR) and other critical care societies from around the world to direct the research response.

\section{Challenges Involved in Conducting RESEARCH}

There are several obstacles to the rapid deployment of a research response in India. We will describe some of the more prominent challenges. The ICMR in 2017 published the National Ethical Guidelines for Biomedical Research and Health Research involving human participants, ${ }^{15}$ which included a section on research in the context of humanitarian emergencies and disasters. This section makes several important recommendations on informed consent, risk minimization, equitable distribution of benefits, privacy and confidentiality, and ethics. Fundamental to these recommendations is the abiding principle of upholding patient interests and ensuring that the research proposed is of the highest quality and validity. While pandemic scenarios such as COVID-19 make the timely deployment of research imperative, this must in no way compromise patient safety or research integrity.

The guidance document recommends that the ethics committees (ECs) have mechanisms in place for expedited ethical clearance and suggests way to ensure this. At each site, the ISCCM and the investigators must liaise with the ECs in their own hospitals/ research institutes and across the country to fast-track approvals. Proposals that are investigator initiated, context relevant, patient focused, and scientifically robust with minimal commercial or extraneous influences would provide ECs the necessary confidence to provide such expedited approvals.

There are other regulatory challenges that are true for, but also equally applicable, outside the context of COVID-19. For instance, the current rules for compensation in clinical trials ${ }^{16}$ are complex to apply or interpret in the case of acute/critical illness. Illnesses that bring patients to the ICU such as severe acute respiratory distress syndrome (common presentation with COVID-19) or stage 3 acute kidney injury (also a potential component of COVID-19) have intrinsic short-term mortality rates $\geq 50 \%{ }^{17,18}$ Patients have, thus, a high risk of dying with/without participation in a clinical trial. These compensation guidelines stipulate that all potential trial-related adverse events should be compensated. While this well-meaning approach is designed to prevent exploitation of trial participants and makes abundant sense in the context of industry-led trials of experimental therapies, they are in no way applicable for a trial of an intervention such as proning. The rules as currently framed are illthought-out, serve as impediments to the conduct of high-quality investigator-initiated trials (which ultimately benefit patients) and are biased in favor of public academic institutions. In the context of critical care, the Government of India and ICMR must recognize that high-quality critical care is delivered in several private institutions ${ }^{19}$ that serve large swathes of the lower and upper middle class in India, and these hospitals and clinicians can be valuable allies in advancing the science. The ISCCM must work in close collaboration with ICMR to enable the revision of these guidelines to reflect the realities of critical illness.

Other challenges include the lack of research infrastructure across hospitals and institutions in India. The pandemic provides a unique opportunity to establish mechanisms for the conduct of research and develop innovative solutions that are context-specific. For example, physician assistants, ward secretaries, and nursing educators could be co-opted into the role of part-time research assistants or data collectors. Several ICUs already adopt this approach, and this could be expanded. Mechanisms must also be identified to incentivize these healthcare professionals for their contributions. The ICMR in coordination with ISCCM can help create a cadre of research coordinators at the ICU or hospital level with provision for training and certification in important research-related skills. Private institutions, on their part, must prioritize research in addition to clinical service provision and enable motivated doctors to transition to clinicianscientist roles. Research output and initiatives should be incentivized and seen as valuable contributions by employers.

\section{Conclusion}

COVID-19 represents an unprecedented public health crisis. However, it also presents a never-before opportunity to develop vital critical care epidemiological and research collaborations, 
establish research infrastructure, and reframe regulatory guidelines. As the oft-cited quotation goes (attributed to various sources including Winston Churchill) "Never let a crisis go to waste", we must seize this opportunity for the improvement of patient care in India.

\section{Acknowledgment}

The authors would like to thank Dr Lakshmi Ranganathan, Research Manager, Department of Critical Care Medicine, Apollo Hospitals, for her inputs and assistance on the manuscript.

\section{References}

1. Available from https://www.who.int/emergencies/diseases/novelcoronavirus-2019 (accessed on 23rd March 2020).

2. Available from https://www.who.int/dg/speeches/detail/whodirector-general-s-opening-remarks-at-the-media-briefing-oncovid-19---11-march-2020 (accessed on 23rd March 2020).

3. Available from http://covidindiaupdates.in/ (accessed on 24th March 2020).

4. Wu Z, McGoogan JM. Characteristics of and important lessons from the coronavirus disease 2019. JAMA 2020. DOI: 10.1001/ jama.2020.2648.

5. Guan WJ, Ni ZY, Hu Y, Liang WH, Ou CQ, He JX, et al. Clinical characteristics of coronavirus disease 2019 in China. N Eng J Med 2020. DOI: 10.1056/NEJMoa2002032.

6. Available from https://www.cebm.net/global-covid-19-case-fatalityrates/ (accessed on 23rd March 2020).

7. Mathur R. Ethics preparedness for infectious disease outbreaks research in india: A case for a novel coronavirus disease 2019. Indian J Med Res 2020. DOI: 10.4103/ijmr.IJMR_463_20.
8. Available from https://clinicaltrials.gov/ct2/results?cond=COVID 19\&term $=$ SARS-CoV2\&cntry $=\&$ state $=\&$ city $=\&$ dist $=$ (accessed on 23rd March 2020).

9. Available from https://isaric.tghn.org/covid-19-clinical-researchresources/ (accessed on 23rd March 2020).

10. Available from http://irisicuregistry.org/ (accessed on 23rd March 2020).

11. Available from https://isccm.org/chitra.aspx (accessed on 23rd March 2020).

12. Manu Varma MK, Krishna B, Sampath S. Secular trends in an Indian intensive care unit-database derived epidemiology: the stride study. Indian J Crit Care Med 2019;23(6):251-257. DOI: 10.5005/ jp-journals-10071-23175.

13. Available from https://www.remapcap.org/what-is-an-adaptive-trial (accessed on 23rd March 2020).

14. Masse MH, Ménard J, Sprague S, Battista MC, Cook DJ, Guyatt GH, et al. Lessening organ dysfunction with Vitamin C (LOVIT): protoco for a randomized controlled trial. Trials 2020;21(1):42. DOI: 10.1186/ s13063-019-3834-1.

15. Available from https://www.icmr.nic.in/guidelines?field_select_ disease_tid=97 (accessed on 23rd March 2020).

16. Choudhury K, Ghooi R. New rules for clinical trial-related injury and compensation. Indian J Med Ethics 2013;10(3):197-200. DOI: 10.20529/ IJME.2013.058.

17. ARDS Definition Task Force, Ranieri VM, Rubenfeld GD, Thompson BT, Ferguson ND, Caldwell E, et al. Acute respiratory distress syndrome. the Berlin definition. JAMA 2012;307(23):2526-2533. DOI: 10.1001/ jama.2012.5669.

18. Murugan R, Kellum JA. Acute kidney injury. what's the prognosis. Nat Rev Nephrol 2011;7(4):209-217. DOI: 10.1038/nrneph.2011.13.

19. Divatia JV, Amin PR, Ramakrishnan N, Kapadia FN, Todi S, Sahu S, et al. Intensive care in India: the Indian intensive care case mix and Practice patterns study. Indian J Crit Care Med 2016;20(4):216-225. DOI: 10.4103/0972-5229.180042. 